\title{
India-born Nobel Laureates
}

The months of October and November every year are looked forward to with great expectation, by scientific establishments and researchers all over the world, for, during these few weeks, prizes are announced by the Nobel Committee. The scientific community watches with great interest, the announcement of the names of the selected few who have been adjudged to be eligible for the most coveted prize, of great value. There is an aura about this annual exercise which recognizes and awards very exceptional ability in the chosen fields of study.

\section{Alfred Nobel}

Why Nobel earmarked his vast fortune for the institution of these Prizes, and what motivated him to do so is not widely known. Alfred Nobel was born at Stockholm on $21^{\text {st }}$ October, 1833 , and when he was only 18 years, went to the United States to study physics and chemistry and remained there for only four years. On his return to Sweden, strangely, he became interested in the handling of nitroglycerine (discovered in 1843), known to be a high explosive of great strength but very sensitive in the raw state, and unsafe to handle. Mixing this with kieselguhr, a type of porous siliceous earth, Nobel produced a high explosive material which could be easily and safely handled. He named his product as Dynamite in 1867, which was safe to handle for all purposes and would explode only when adequate heat or pressure was applied. The process and the name were patented in Britain (1867) and in US (1868). The extensive use of dynamite in the blasting of rock for foundations of large engineering structures and in mining brought him an immense fortune, and he was also the owner of the noted armaments manufacturing Company - Bofors. Nobel died on 10 December, 1896.

\section{The Nobel Prize}

Strange are the ways of the world! Nobel is stated to have been a man of peace, a reader, a lover of literature, and remained unmarried. He had hoped that the tremendous destructive power of the material he had created would bring an end to armed conflicts, and to further his wish, he left the bulk of his fortune for the establishment of a fund to provide valuable prizes, to be given annually, 'to those who during the preceding year had conferred the greatest benefit on mankind in the fields of physics, chemistry, physiology or medicine, literature, and peace'. An additional award for economics was established in 1968 by the Bank of Sweden.

\section{The India-born Laureates}

The first award was made in 1901, and the most recent, one hundred and eight years later. During this period, only two - Poet Rabindranath Tagore (1915) and Chandrasekhara Venkata Raman (1930) were India-born and their field of activity entirely Indian. Other awardees were 
no doubt born in India, but migrated to either Britain or America and pursued their scientific investigations into problems which had no connection with India. Hargobind Khorana (1968, Physiology), Subrahmanyan Chandrasekhar (1983, Physics), and Amartya Sen (1998, Economics) are to be counted among these. There is another category of persons who were born in India such as Abdus Salam, a citizen of Pakistan, but born in undivided Punjab (1979, Physics), and Mohammed Yunus, born in undivided Bengal but who remained in Bangladesh after Partition, who were awarded the Nobel Peace Prize in 2006.

There is a further category of British citizens, but born in India and whose work was primarily concerned with India and its problems. The most noted names in this category are those of Ronald Ross, born in Almora, India, and awarded the Nobel Prize for Medicine in 1902 for his work in the eradication of malaria. An Institute had been established in Hyderabad in 1897 and it was at this institute Ross worked and discovered the malaria transmission cycle and helped in the eradication of malaria affecting millions in India and other parts of the world. Others in this category are Rudyard Kipling, the noted English poet and novelist, born in Mumbai and awarded the Prize in Literature in 1907 and Mother Teresa, of Albanian origin, who became an Indian citizen and worked for the alleviation of the indignities suffered by destitutes, lowly and the lost, was awarded the Nobel Peace Prize in 1979.

\section{The Truly (100\%) Indian Laureates - Tagore and Raman}

The only two personalities qualified for the Nobel Prize who were not only born in India and laboured and devoted their life to the advancement of India and its cultural heritage in the fields of

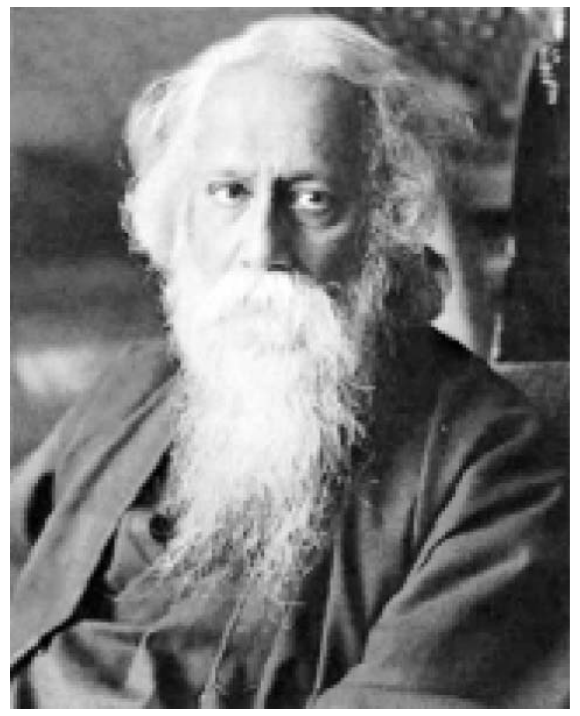

literature and science were Rabindranath Tagore (1913) and Chandrasekhara Venkata (C.V.) Raman (1930). Both were towering personalities whose work will be remembered for generations to come. The songs of Rabindranath Tagore have been sung by millions in Bengal, and through their translation, over the rest of India. The small book of songs 'Gitanjali', through its English translation, 
took the outside literary world by its charm. Its exotic beauty, its novelty of expressions, preserved even in the English translation, took the English literary world by storm, and Tagore suddenly shot up to fame both in the East and the West. He was unable to receive the Prize in person and sent the following telegram to Stockholm:

"I beg to convey (to) the Swedish Academy of Science my grateful appreciation of the breadth of understanding which has brought the distant near and has made a stranger a brother..."

"As a recognition of individual merit it was of great value, no doubt; but it was the acknowledgement of the East as a collaboration with the Western continents in contributing its riches to the common stock of civilization, which had the chief significance of the present age. It meant joining hands in comradeship by the two great hemispheres of the human world across the sea".

Tagore, however, died a disappointed man. The insolence of power had murdered and wounded a large number of his fellowmen fighting for their freedom. In anguish, he discarded the Knighthood conferred on him by the Queen of England, and, in his final years (on his $80^{\text {th }}$ birthday), wrote:

As I proceed onward, I look behind to see the crumbling ruins of civilization strewn like a vast dung heap of futility. And yet I shall not commit the grievous sin of losing faith in man. I would rather look forward to an opening of a new chapter in his history after the cataclysm is over and the atmosphere is rendered clean with the spirit of service and sacrifice. Perhaps that dawn will come from the horizon, from the east, where the sun rises.

He was highly critical of blindly adopting western models, characterizing such practices as 'rag picking from others' dustbin'. In one of his verses he wrote:

$$
\begin{aligned}
& \text { Be not ashamed my brother to stand } \\
& \text { Before the proud and the powerful } \\
& \text { With your white robe of simpleness } \\
& \text { Let your crown be of humility. } \\
& \text { Your freedom, the freedom of the soul, } \\
& \text { Build God's throne daily upon } \\
& \text { The ample bareness of your poverty } \\
& \text { And know that what is huge is not great } \\
& \text { And pride is not everlasting }
\end{aligned}
$$

Writing about the moral force of Gandhi and the non-violent way he fought for Independence, he said:

It is in the fitness of things, that Mahatma Gandhi, frail in body and devoid of all material resources should call up the immense power of the meek that has been waiting in the heart of the destitute and insulted humanity of India. The destiny of man has chosen for its ally the power of soul and not of the muscle. And she is to raise the history of man from the muddy level of physical conflict to the higher moral altitude.

We the famished, ragged and ragmuffins of the east, are to win freedom for all humanity. ..... I have seen the west, I covet not the unholy feast in which she revels in every moment, growing more and more bloated red and dangerously delirious. Not for this is the mad orgy of midnight with lighted torches, but awakenment in the serene light of the morning. 
These random examples of the writings of Tagore will give an idea of the poetical excellence and a loftiness of approach strong in its appeal. His burning nationalism and yearning to see his country scale greater heights in all fields, not by blind imitation of western models but sustaining inspiration from the cultural heritage of India, were inspiring. It is strange that none of his poems find a place in anthologies of the best of English poetry. The essence of Indian culture seems to have eluded the English-reading public. This apart, India can be truly proud of the world recognizing Tagore as a Laureate. He transcended the geographical boundaries of Bengal and stood as the poet par excellence of Bharath.

\section{The One and Only Chandrasekhara Venkata (C.V.) Raman}

Another great personality, one hundred percent Indian, was Chandrasekhara Venkata Raman. If, today, Bangalore has emerged as the Science City, attracting intellectuals from all parts of the world, it is in no small measure, the result of seeds sown by Raman nearly hundred years ago.

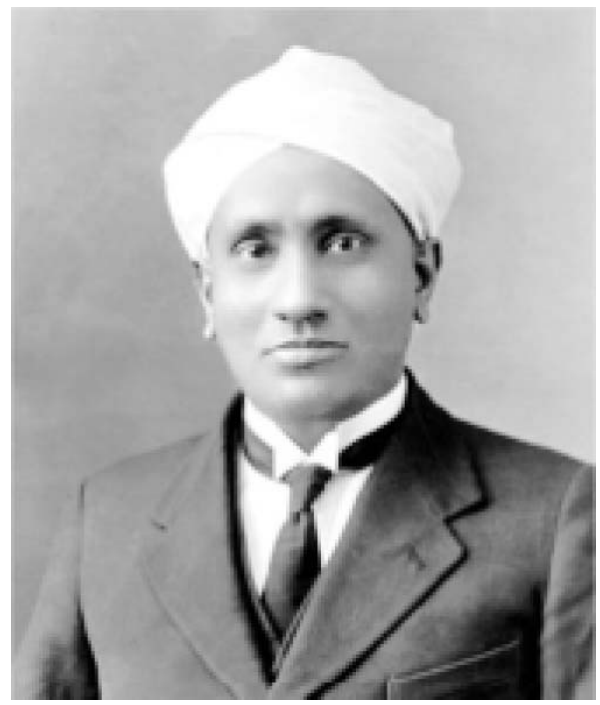

His science was simple and did not require millions of rupees and a grand laboratory equipped with state of the art instruments imported at great cost. With only a pocket spectrometer and reflected sunlight providing a beam, he gave science a most powerful tool, a new eye to explore Nature. He was a celebrity in India, almost as famous as Gandhi, and remained a colourful personality in the field of science throughout his life. The surprising fact is that in his education, he owed nothing to direct contact with physicists outside of India. His formal training was entirely in India.

After graduation, he appeared for a competitive examination and secured a highest paid job open to an Indian in the financial services of the Government of India. He however, left the job in preference to an offer of a senior position in Calcutta University which was to give him enough freedom with full scope to the development of his thoughts. A private laboratory gave him a place 
to work and he started his experiments. Surrounded by a devoted bunch of young men fired with his dynamic enthusiasm, the atmosphere in the laboratory was fully charged with expectation that something great would emerge out of all their research.

Moments of discovery can be the most exhilarating in a scientist's life. The desire to observe and understand that which no one else has ever observed or understood before, was one of the forces that kept Raman rooted to the laboratory. Few discoveries come in a flash. It takes months or years of struggle. In the case of Raman, it was guided by intensive enquiry with support neither from sophisticated instruments or from outside experts and is a triumph of Indian intellect at its finest hour. Considering the good work he had already done, the Royal Society conferred on him the coveted Fellowship. When asked 'what next', Raman had the supreme confidence and audacity to reply 'Nobel Prize, of course'. His extraordinary ego was characteristic of him.

'Nature', the famous science magazine, first appeared on $4^{\text {th }}$ November, 1869. In the latest issue (vol.462, 5 Nov. 2009), it carries a two page note on miscellany from 1889, 1909, 1929, 1949, 1969 and 1989. The note for $4^{\text {th }}$ November, 1909, includes a photograph of young Raman: "A 20 year-old Chandrasekhara Venkata Raman writes from India about vibrations in acoustics, one of his preoccupations. His greater fame rests on his subsequent discovery of a "new kind of radiation or light emission from atoms and molecules" - the Raman Effect - for which he won a Nobel Prize in 1930".

We cannot think of any other instance of a young man, hardly out of college, without the guidance of his professor, and even without his knowledge, sending letters to magazines of the reputation of Nature, Philosophical Magazine and Physics Today, and getting them published. This self-confidence and assurance are truly amazing.

The first demonstration of the scattering of light when a powerful beam was passed through a transparent medium with the production of characteristic lines, which are related to the atomic structure of the medium, was of fundamental importance and came to be known as the 'Raman Effect'. The results of this investigation were first announced in a lecture delivered at the Central College, Bangalore. The importance of his work was at once realized by the scientific community and won for him the Nobel Prize in recognition of the outstanding merit of the new discovery.

Just as Gandhi achieved not only greatness himself, but inspired a whole team of able leaders for the next generation, Raman inspired and trained a number of young men full of ability and willing to push forward and take up leadership after him. The 'Raman Effect' was immediately overtaken by developments in the field of physics and entered the pages of history during his lifetime! His work has proved to be posthumously highly productive. 
The story of what happened later, the heaps of congratulatory messages received from the Viceroy and others, the circumstance of Raman being so sure of the Nobel Prize that he had booked two tickets, one for himself and the other for Lokasundari Raman, to Stockholm, for the Prize-giving ceremony, and the graciousness and the dignity of his reply are legendary and need not be repeated here.

Raman lived to see many good and bad things in his later years. He started the Physics Department at the Indian Institute of Science, Bangalore, and the bitter controversy that followed forced him to step down. He also started building a new Institute of Research for himself. The Indian Academy of Sciences immediately followed. He nursed these Institutions with devotion and care, became a legend in his own lifetime and died full of years, mourned by one and all as an iconic figure, full of majesty and dignity, a true Laureate par excellence. Raman needed no decoration and no recognition to add to his uniqueness. He was a distinguished scientist even before he received the Fellowship of the Royal Society and the Nobel Prize for Physics and also had a great sense of humour. Having taken to the western style of living, he persisted in wearing a turban and Raman's turban became as famous as his discovery and his Nobel Prize. When he was asked why he wore a turban, quick came his retort, 'why! to prevent the head from bursting'. That was Raman!

It is pointless to recount the contributions to science of other 'Indian' recipients of the Nobel Prize, for, no part of their work was related to India. Although they were born in India, their higher education was in US or UK, their field of activities were in no way connected with India or in finding solutions to its numerous problems. Even the latest awardee, Venkataraman Ramakrishnan, is no exception. Born in Chidambaram he had his education at Vadodara and left for US for further studies. His research was carried out in the Ohio University, USA, which earned for him, Ph.D in physics. In 1999, he joined the MRC Laboratory of Molecular Biology at Cambridge, a most prestigious laboratory, where he worked with others on the structure of ribosomes, which apparently had important applications in the development of more effective antibiotics. Obviously, it is a field of creative research and the Nobel Committee chose the three persons involved, Ada Yonath (Israel), Thomas Steitz (Yale) and V. Ramakrishnan, to share the honour.

\section{Venkataraman Ramakrishnan}

The most surprising part is that Venkataraman Ramakrishnan's talent was not recognized during his youth by the scientific community in India until the award of the Nobel Prize. The several scientific academicians of India failed to recognize his talent and did not take the initiative of electing him as one of their fellows. There is, unfortunately, hardly any effort at recognizing youthful talent and at providing incentives for its development. The principal requisite for success in scientific research, Raman used to say: "is not the maturity of knowledge associated with age and experience but the freshness of outlook which is the natural attribute of youth". The principal 
function of the elder generation of scientific men is to discover such talent and genius in the younger generation and provide ample opportunities for its free expression. The example of Venkatraman Ramakrishnan is another instance of the failure of the elderly scientific community in India to recognize youthful talent and give it full scope for development. The mathematical prodigy, Srinivasa Ramanujan, first had to slave as a Clerk in a Port Trust office, and it was given to Cambridge University to recognize his merit, invite him to Cambridge, bearing all his travel expenses and create an atmosphere for the flowering of his inherent talent. This was so effective that within a year of his arrival in Cambridge, he was elected a Fellow of the Royal Society and recognized as a great mathematician by the entire world. It is no wonder that Cambridge, with its tradition of recognizing and nurturing talent, has the unique distinction of producing 85 Nobel Laureates, the latest addition being Venkatraman Ramakrishnan. There is an abundance of Indian talent in the younger generation, only awaiting the required guidance and leadership.

Let me end this note with the inspiring lines of the great poet of India, Rabindranath Tagore, and the first to be decorated with the Nobel Prize.

Where the mind is without fear and the head is held high

Where knowledge is free

Where the world has not been broken up into fragments by narrow minded domestic walls

Where words come out from the depth of truth

Where tireless striving stretches its way towards perfection

Where the clear stream of reason has not lost its way in the dreary desert sand of dead habit;

Where the mind is led forward by thee into ever-widening thought and action

Into that heaven of freedom, my father, let my country awake. 